\title{
EL MÉTODO DE PENSAMIENTO CÍVICO-ANÁRQUICO DE CHARLES PÉGUY
}

\author{
Charles Péguy's civic-anarchic method of thinking
}

\section{RESUMEN}

¿Es posible un pensamiento anárquico que, al mismo tiempo, sea cívico, constructor de la polis? Es lo que ha sostenido Charles Péguy a través de la formulación de tres reglas metodológicas para bien conducir el pensamiento anárquico-cívico. Estas son la autoridad de competencia universal de la razón del sujeto; la libertad del pensamiento; el arraigo de ambas en una memoria que genera el acontecimiento del pensamiento. Este método anárquico-cívico permite pensar de modo nuevo los factores que fundamentan a la polis.

Palabras claves: Charles Péguy, método, civismo, anarquismo, libertad, memoria, polis.

\section{ABSTRACT}

Is it possible that an anarchic thought, be at the same time, civic, builder of the polis? This is what Charles Péguy has argued through the formulation of three methodological rules to properly conduct the anarchic-civic thinking. These are the universal competence authority of the reason of the subject; the freedom of thought; the rooting of both in a memory that generates the thought event. This anarchic-civic method allows thinking in a new way, the factors that support the polis.

Keywords: Charles Péguy, method, civism anarchism, freedom, memory, polis.

\section{UNIVERSUM}

Revista de Humanidades y Ciencias Sociales

\section{AGOSTINO MOLTENI}

Instituto de Teología, Universidad Católica de la Santísima Concepción. Concepción, Chile. Correo electrónico: amolteni@ucsc.cl

Artículo recibido el 9 de julio de 2018.

Aceptado el 10 de mayo de 2019. 


\section{INTRODUCCIÓN}

¿El pensamiento anárquico está en contradicción con la construcción de la polis o puede constituirse en pensamiento cívico, constructor de la ciudad de los hombres?

De modo general, el anarquismo es clasificado como un fenómeno irracional y se confina en el ámbito de un pensamiento utópico que no puede ofrecer ningún aporte para esta construcción. Sin embargo, Charles Péguy (1873-1914) ha sostenido exactamente lo contrario. Aunque haya sido clasificado de modo impropio solo como poeta, Péguy es en realidad un pensador riguroso, un filósofo. Según el juicio de Finkielkraut "es uno de los grandes pensadores del mundo moderno y, sin duda alguna, tiene la misma estatura que Nietzsche, Benjamin, Heidegger" (1992: 59).

En este artículo queremos mostrar en qué sentido Péguy ha podido sostener que solo un método de pensamiento anárquico puede constituir un aporte para la construcción de la que él llamaba la cité harmonieuse (Péguy, 1987: 55-117; Molteni, 2007a). Aunque sin tematizarlos de manera explícita, ha mostrado algunos núcleos metodológicos de este pensamiento capaz de construir una civitas libre de cualquier despotismo, o sea, "capaz de poner remedio al mal universal" (Péguy, 2014: 3-4). Señalar estos núcleos es la intención de nuestra investigación.

Varios estudios ya han analizado el anarquismo de Péguy desde el punto de vista político, en su relación con el socialismo y con las distintas corrientes anárquicas francesas y sus autores (Cahm, 1978; Leroy, 1978; Bastaire, 1979; Wilson, 1979; Grondeux, 2002; Vitry, 2015). Mounier, que se consideraba heredero del pensamiento de Péguy, en su escrito Comunismo, anarquía, personalismo (1973) donde mira con simpatía el pensamiento anárquico cita solo de modo extremadamente genérico a nuestro autor. Esto significa que no se ha puesto una atención adecuada en la originalidad de los núcleos metodológicos de su pensamiento anárquico y al mismo tiempo cívico.

Antes de entrar en el contenido específico que nos interesa, hay que señalar de modo muy sintético las razones históricas por las cuales Péguy se 
ha definido como anárquico.

Si bien nuestro autor vive en un período histórico en que, en Francia, a finales del siglo XIX, la atención está concentrada en el "fenómeno espectacular del anarquismo" (Cahm, 1978: 108) con sus atentados, sus obras teóricas, sus revistas e iniciativas culturales-sociales (Maitron, 1951) y aunque conozca a Jean Grave y afirme que su obra La societé mourante et l'anarchie (1893) lo ha "conmocionado profundamente" (Péguy, 1987: 684)1, en su obra "están casi totalmente ausentes los contenidos de los teóricos anárquicos" (Wilson, 1979: 25).

Esto significa que su anarquismo no es una adhesión intelectual a contenidos abstractos, sino que más bien ha sido engendrado por acontecimientos histórico-político-filosóficos.

El primero es el famoso affaire Dreyfus. Después de que Péguy se ha alistado entre los socialistas, en la convulsión de este affaire, no solo ve la inercia de estos, sino que reconoce que entre los pocos que se han comprometido apoyando a Dreyfus están los anárquicos (Péguy, 1987: 5253). Por esta razón se separa del socialismo oficial-partidario-politiquero y "el compromiso dreyfusard es su primer acto de anarquismo" (Wilson, 1979: 39).

En segundo lugar, frente a la decisión del Congreso Socialista francés de impedir cualquier publicación que no sea oficialmente reconocida por la cúpula del partido, funda en 1900 sus famosos Cahiers de la Quinzaine, acto por el cual es acusado por Lucien Herr, uno de los jefes socialistas, de “insubordinación”, de ser "anárquico" (Péguy, 1987: 657), mientras que, para Péguy, ser anárquico es el único modo de "salvar el socialismo original" (Seigle, 2014: 93).

En tercer lugar, Péguy rechaza de modo tajante el dogma dominante en su tiempo acerca de que el único método de conocimiento es el científico. Por eso, prolongando en un cierto sentido a Descartes, Péguy quiere elaborar un “método para conducir bien a la razón” (Péguy,1992: 1273), un método para

1 Todas las traducciones de los textos de Péguy y de los otros autores citados cuyas obras no están en castellano, son mías. 
un pensamiento que sea el de "una moral cívica" (Péguy, 1992: 1246), pues lo que le interesa es la construcción de la "ciudad armoniosa".

\section{LAS REGLAS DE UN MÉTODO DE PENSAMIENTO CÍVICO- ANÁRQUICO}

Señalamos ahora los núcleos de este pensamiento anárquico-cívico.

\section{AUTORIDAD DE COMPETENCIA DEL SUJETO VS. AUTORIDAD DE MANDO}

Péguy, en 1904, dicta tres conferencias sobre el anarquismo político. Las define como "el ensayo de un método para comenzar a trabajar en los estudios sociales" (1987: 1795) y, en ellas, distingue la que llama la "autoridad de competencia" que apela a la razón, de la "autoridad de mando" que apela a la fuerza. Para Péguy hay un solo método sano de pensamiento, el de la autoridad de competencia del sujeto-hombre. El método, en esto Péguy es claro, son los pasos del camino que la razón debe dar para bien conducirse a sí misma. En esto es fiel discípulo de Descartes y del mismo Bergson: "El bergsonismo es un método para bien conducir la razón" (Péguy, 1992: 1273). Es más, estos pasos tienen un criterio interno que es propiamente cívico, el de una "moral cívica" (Péguy, 1992: 1247), es decir, pueden ser juzgados como razonables o irracionales solo en cuanto contribuyen a la construcción por parte del sujeto-hombre de la cité harmonieuse.

La autoridad de mando está en contra de la razón, pues quiere imponerse al sujeto por los caminos, es decir, por los métodos de la sinrazón, por una especie de fideísmo (Cahm, 1978: 14). Caminos-métodos señalados detalladamente en su escrito de 1901 De la raison (Péguy, 1987: 834-853), un "breviario de lucha antitotalitaria" (Bastaire, 1979: 30). Estos caminos combatidos por las doctrinas anárquicas clásicas (Cahm, 1978: 111) son representados por la razón de Estado, por la autoridad de mando militar, gubernamental y parlamentaria. Además, Péguy agrega la autoridad de mando 
democrática (Péguy, 1988: 837), la de una supuesta “minoría creadora" (idea sostenida en ámbitos anárquicos según Cahm, 1978: 116) y la autoridad de mando religiosa: "La razón no necesita, ni quiere ninguna Iglesia. No puede y no debe existir una Iglesia de la razón. No hay un clérigo de la razón” (Péguy, 1987: 836-837).

Hay que notar que, para Péguy, esta autoridad de mando de tipo clerical estaba presente entre los mismos socialistas que querían vincular la liberación económica de los hombres (lo que para Péguy debía ser solo una finalidad preliminar del socialismo) a un sistema socialista, a la "autoridad socialista" (Péguy, 1987: 340). Puesto que, para él, socialismo y anarquismo no están en contradicción, Péguy combate aquí la pretensión clerical-autoritaria y socialista-politiquera: "Vincular el socialismo a un sistema científico, artístico, filosófico, es literalmente cometer un abuso de confianza hacia la humanidad. (...) Por una liberación, introducir una esclavitud” (Péguy, 1987: 840).

Otras autoridades de mando son las de la sospecha, de los historicistas y de los pedagogos, de los periodistas con su "clientela" (Péguy, 1987: 845-846; Molteni 2006a) y de los revolucionarios del terror. Todas estas autoridades de mando con sus pretendidas "sanciones sobre-científicas" (Péguy, 1988: 260) idolatran la razón y son paradójicamente clericales, pues "erigen altares, hacen oraciones, tienen sus sacerdotes que elaboran el culto de la diosa Razón” (Péguy, 1987: 836). En esto Péguy sigue a Proudhon que había escrito a Marx: "No nos constituyamos en apóstoles de una nueva religión, aunque dicha religión fuese la religión de la razón” (Bastaire, 1979: 31).

En contra de esta autoridad de mando despótica, la que él llama "la audacia de la incompetencia" (1988: 1103), Péguy sostiene la legitimidad racional de la "autoridad de competencia" del sujeto-hombre que se presenta como la primera regla metodológica de su pensamiento cívico-anárquico. Como se ha señalado, para Péguy, la autoridad de competencia coincide con la elección del "anarquismo contra el autoritarismo" (Daudin et al., 2013: 50).

Ante todo, la autoridad de competencia del sujeto usa la razón de modo razonable y no está en contra de la razón. La autoridad de competencia “escucha la voz de la razón” (Péguy, 1987: 687), lo que no hacen los violentos 
“anárquicos profesionales” (Péguy, 1987: 683) y está bien atenta a no mezclarla con la fuerza puesto que, de esta forma, "no es la fuerza que queda ennoblecida por su comunicación con la razón, sino que es esta última quien se envilece por su promiscuidad con la fuerza" (Péguy, 1987: 1816). A este propósito, en las tres conferencias sobre el anarquismo, Péguy se declara no solo anárquico, sino acratista, pues rechaza cualquier tipo de fuerza (krátos) que quiera imponerse sobre los argumentos de la razón razonable que trabaja lealmente.

Esta autoridad de competencia del sujeto es la de las "individualidades sin mandato" (Péguy, 1992: 314), ya sea gobernativo, parlamentario o partidario. A este respecto, Péguy condena a los que llama los "anárquicos de gobierno" que, si bien dicen estar en contra del Estado, se dejan prebendar por este convirtiéndose en "anarquistas de Estado", que "pasan a la caja del Estado" para recibir su salario de “anarquistas-funcionarios" (1987: 894-895).

Sin mandatos y ajena a cualquier prebenda, la autoridad de competencia es cívico-anárquica en cuanto consiste en la autoridad del hombre competente a nivel universal. De este modo, el sujeto-hombre es el primum ius, la primera fuente del derecho. Ahora bien, para Péguy, esta autoridad no pertenece al individuo entendido en sentido solipsista, sino que es la del hombre del pueblo, el de la raza francesa antigua que él ha conocido, la del hombre que “juzga como un Papa” (Péguy, 1988: 192) y que ejerce su jurisdicción sobre la realidad entera puesto que "es la suprema jurisdicción” (Péguy, 1992: 76). De este hombre, del civis-ciudadano, nace la civitas, la cité harmonieuse.

En este sentido, se podría aplicar a la autoridad de competencia que Péguy defiende la afirmación de Ulpiano: Quod principi placuit, legis habet vigorem, claro está, no en cuanto referida al príncipe de un poder dictatorial. La autoridad de competencia del hombre es propiedad-poder-capacidad del sujeto que es legibus solutus, desvinculado de una ley impuesta por una autoridad de mando. Esta última puede ser el krátos de algunos ("aristocracia", es decir, el poder de algunos sujetos supuestamente sagrados: científicos, políticos, intelectuales, etc.) o de todos (poder del pueblo, democracia: la de los números de la mayoría, del sufragio universal); poderes que Péguy ataca 
en sus tres conferencias sobre el anarquismo (1987: 1800-1801).

Hay que notar que, respecto de un supuesto poder político del pueblo, Péguy “se asimila al anarquismo marxista, antiautoritario, que se oponía no solo a la democracia burguesa-capitalista, sino al socialismo marxista que confiaba en el sufragio universal" (Wilson, 1979: 10-11). Sin embargo, aunque Péguy esté en contra del sufragio universal entendido como método para establecer quién tiene la razón y como método "para establecerse en el poder" (Wilson, 1979: 11), siempre asistió a votar a las elecciones políticas (Péguy, 1987: 685), puesto que su anarquismo es "profundamente republicano" (Wilson, 1979: 34). Diferenciándose de los anarquistas, Péguy "no rompe con la política" (Cahm, 1978; 115), con un pensamiento que quiere construir la polis, sino más bien con la politiquería de todo tipo.

Ahora bien, ¿esta autoridad de competencia en qué se fundamenta? Péguy lo afirma claramente: "La cuestión de lo que conviene o no conviene a la razón, es solo por el trabajo de la razón que nosotros podemos plantearla" (Péguy, 1987: 853). Ne convient pas, "no conviene": esta expresión que indica el principio de conveniencia que usa la razón está dondequiera en su obra Marcel, De la cité harmonieuse. El principio de la conveniencia es el criterio de juicio usado para la construcción de la ciudad armoniosa donde cada sujeto “puede realizarse según su belleza personal” (Péguy, 1987: 77).

De este modo, la autoridad de competencia anárquica que Péguy defiende es la capacidad-poder del sujeto de juzgar-imputar el universo entero (hombres, doctrinas, sistemas, políticas, etc.) por su conveniencia con la razón crítica. Afirmar que todo el poder es del sujeto, que es el primum ius, significa para él entender el "poder" como verbo, como poder-capacidad-virtus del sujeto de pensar y legislar universalmente urbi et orbi como un Papa.

En este sentido, se puede decir que, afirmando la autoridad de competencia, Péguy invita a reformular el concepto de laico: lejos de cualquier contraposición clerical, el laico es el sujeto-hombre capaz de un juicio universal, sin necesitar de poderes místicos-misteriosos-sagrados: "La competencia no tiene nada de misterioso o de desconocido-extraño" (Péguy, 1988: 1165). Se trata de una capacidad de "vida práctica y cívica" (Péguy, 
1988: 1169). De hecho, el anarquismo de Péguy consiste, como él mismo afirma, en querer "universalizar todas las sanas libertades individuales de pensar" (1987: 348). No se trata de legitimar el individualismo solipsista, sino que de afirmar que cada sujeto, en virtud de su autoridad de competencia, tiene el poder de juzgar, de ser fuente de legislación universal. En este sentido, Péguy ensancha la afirmación de Kant para el cual el sujeto, el hombre laico, es norma de legislación moral universal dándole un sentido más bien cívico.

Este poder del pensamiento del sujeto es propiamente un trabajo crítico de la "razón que trabaja" (Péguy, 1988: 852) con el principio de conveniencia. Trabajo que implica la crítica de la tradición recibida, de la heredad del pasado. Escribirá: "Yo rechazo la heredad en bloque. Es necesario el beneficio de inventario" (1987: 278; 1988 388), lo que significa "rechazar de modo resoluto el hecho de inclinar la razón frente a lo que no es conforme a la razón" (Péguy, 1987: 291-292). El pensamiento anárquico, entonces, rechaza cualquier inhibición del pensamiento por parte de poderes que pretenden ser considerados a priori como "sagrados", como inimputables por la razón y su criterio de conveniencia:

No hay verdades sagradas, es decir, prohibidas a la plena investigación del hombre. (...) Ningún dogma debe limitar el esfuerzo perpetuo y la perpetua búsqueda de la razón humana. (...) Y, si Dios mismo se levantara, visible sobre la multitud, el primer deber del hombre será el de rechazar la obediencia y tratarlo como igual, alguien con quien se discute, no como el amo que se soporta (Péguy, 1987: 385$386)$.

La primera regla, es decir, el primer momento-movimiento de un sano pensamiento anárquico-cívico coincide, por tanto, con el rechazo por parte del sujeto de ser inhibido en su autoridad de competencia por cualquier episteme, por cualquier saber que pretende ser un saber superior (epi) y que representaría un ámbito de poder sagrado donde la razón y su criterio de conveniencia es inhabilitada en su juicio. Es la reformulación péguyana del concepto del hombre laico. 


\section{LIBERTAD DEL PENSAMIENTO}

Ya hemos señalado que, lejos de presentarse como un subjetivismo individualista — como el de Max Stirner y su único solipsista: Vitry- (2015: 121-122), el método de pensamiento anárquico de Péguy es, más bien, lo contrario ya que requiere lo que él llama partenaires, es decir, socios: una amistad del pensamiento. La autoridad de competencia, al mismo tiempo que rechaza cualquier autoridad de mando, requiere ser compuesta cívicamente con otros pensamientos.

Para entender este punto hay que notar que Péguy afirma que la autoridad de mando genera solo los partisans, los partidarios-aduladorescortesanos de aquellos que tienen "El Poder" político o intelectual (Péguy, 1987: 837). Es la "fidelidad de los parásitos" (Péguy, 1987: 725) que hacen consistir su seguridad en un sistema ya hecho -político-filosófico-teológico-Para él existen solo dos tipos de hombres: los que quieren tener partisanos, es decir, "los que quieren ejercer una autoridad de mando, una dominación sobre los hombres"; y los que "piensan solo en regocijarse en la felicidad de los otros hombres" (Péguy, 1987: 546-547).

Ahora bien, la autoridad de competencia, lejos de cualquier absolutización del individualismo, "no admite rivalidad, sino que solo cooperación y colaboración" (Péguy, 1987: 847). Esta es la segunda regla del método del pensamiento anárquico de Péguy que se fundamenta en la lógica del partenariat, es decir, de la libre asociación con cualquier otro sujeto (no excluyendo al mismo Dios, si este demuestra su existencia en la historia: Péguy, 1987: 386) que se proponga como productor de beneficios universales, o sea, de una justicia universal. De hecho, Péguy define su socialismo anárquico como una "filosofía de los productores" (1988: 462-464) en la misma línea de Marx, de su amigo Sorel y de Pelloutier (Bastaire, 1979: 22).

Este método de pensamiento anárquico consiste en el trabajo compuesto entre los hombres, en que cada sujeto colabora, coopera con el pensamiento del otro. Los mismos hombres que comandan en la cité harmonieuse, cumplen "el trabajo de mandar" (Péguy, 1987: 65). Esto significa que no hay autoridad 
de mando donde hay trabajo compuesto con otros hombres. Esta colaboración y cooperación, es decir, esta amistad del pensamiento en vista de la producción de beneficios universales, impide lo que Péguy odiaba en Jaurès y en los socialistas "una unidad artificialmente creada e impuesta autoritariamente" (Wilson, 1979: 16).

Esta colaboración y cooperación propuesta por Péguy consiste en actos puestos y compuestos entre los hombres. A este respecto, Péguy no reconoce ninguna ontología presupuesta en el hombre y es equivocado afirmar que "Péguy supone que el hombre es solidario" (Wilson, 1979: 14), es decir, que lo sea por naturaleza. Por otro lado, tampoco se puede decir que Péguy "funda su ideal social sobre la bondad virtual del hombre" (Cahm, 1978: 112) puesto que Péguy sigue en este punto a Grave, para el cual "el hombre está lejos de ser un ángel” (1893:125), afirmación que nuestro autor retomará a menudo. Para Péguy, "en la ciudad armoniosa los hombres no trabajan contra otros, sino con otros" (Péguy, 1987: 71), lejos de cualquier envidia, competitividad, emulación, rivalidad, guerra pública y privada, ambición, cólera, venganza, resentimiento, maldad. Si Grave había escrito que los trabajadores, "forzados a luchar, se consideran enemigos entre ellos" (1893: 124), Péguy es categórico en afirmar que "toda lucha es burguesa y la lucha de clases es burguesa como todas las demás, pues es más bien una concesión del socialismo a la burguesía" (Péguy 1987, 357). Este rechazo de la violencia es uno de los tratos que más distinguen el pensamiento anárquico de Péguy del de Bakounin y de Kropotkin (Cahm, 1978: 113).

La regla de la colaboración y de la cooperación no excluye de su ciudad armoniosa ningún hombre que haga un trabajo bien hecho, burgueses incluidos (Péguy, 1987: 323). Por esta razón Péguy condena a los sindicalistas anárquicos (Wilson, 1979: 30) y a las organizaciones de trabajadores que son favorables al sabotaje y a la huelga. Para él, "los carpinteros de Orleáns, gente pobre y simple, son más profundamente revolucionarios que la Confederación general del trabajo" (Péguy, 1988: 457), pues estos carpinteros trabajan con y no en contra de otros hombres, haciendo su trabajo bien hecho. A este propósito, si Péguy menciona favorablemente a un grupo anárquico como 
los "Estudiantes colectivistas" de París, se debe al hecho que "son serios, trabajadores, con un conocido trabajo interior de pensamiento" (1987: 237), lejos de ser unos meros destrozadores.

Esta regla del partenariat entre los hombres que hacen su trabajo bien hecho con otros hombres, se puede definir como la de la libertad del pensamiento, bien distinta de una relativista-nihilista libertad de pensamiento. Esta última supone poder pensar cualquier cosa sobre lo real, o tener infinitas perspectivas y puntos de vista para poder agotar todos los detalles, lo que es típico de lo que Péguy llama el vir scientificus que aplica el método positivista (1987: 1399). Para él se trata de "no confundir la cobardía intelectual con el sentido de la libertad, pues un hombre no es libertario porque aprueba un razonamiento falso" (Péguy, 1987: 886). Dicho de otra forma, para él, la libertad cívica no consiste, ante todo, en la posibilidad de elegir en abstracto entre varias posibilidades, ni tampoco en una estéril tolerancia para la cual la libertad de cada uno termina donde inicia la del otro, una libertad entendida en sentido espacial. Como ha escrito Mounier, Péguy no piensa que pueda describirse la libertad individual "en términos de espacio y de yuxtaposición" (1993: 97), menos aún piensa la libertad al modo sartriano, como infierno recíprocamente causado entre los hombres. Para Péguy la libertad consiste en el juicio de conveniencia dado por la autoridad de competencia del sujeto sobre un eventual partenaire-socio.

La libertad del pensamiento es propiamente anárquica y al mismo tiempo cívica, es la libertad de asociarse a cualquier otro sujeto que conviene, es decir, que colabora y coopera lealmente a la autoridad de competencia del hombre. En este sentido, la libertad del pensamiento consiste, ante todo, en no hacer trampas. Esta fue la experiencia de Péguy con sus amigos de los Cahiers (Molteni, 2006b) una amistad "fundada a partir de un acto anarquista" (Vitry, 2015: 135), una amistad en que había "católicos, protestantes, judíos, libres pensadores que no hacían trampas" (Péguy, 1992: 822).

Por otro lado, la libertad del pensamiento es bien distinta de la supuesta liberación socialista que termina en una "servidumbre de los hombres a la mentalidad de los libertadores" (Péguy, 1987: 838-839) y en un "pensamiento 
intelectualmente esclavo, unificado" (Wilson, 1979: 17). A este respecto, como ya hemos observado, el anarquismo cívico de Péguy está en contra de un "socialismo centralizado", de la "disciplina de partido" (Cahm 1978: 109110), de "un Partido que distribuye un pensamiento" (Seigle, 2014: 90) y que, por eso, inhibe la libertad de asociación del pensamiento. $\mathrm{Si}$, como escribe Teyssier, para Péguy "los antagonismos de clase desaparecían frente a la simple amistad" (2008: 99), la cuestión fundamental es "pensar libremente lo que hay que pensar" (Péguy, 1987: 841), es decir, poder pensar en cualquier posible partenariat-asociación conveniente, sin ninguna "autoridad de mando" que imponga una unidad artificial entre los hombres desde afuera o a priori. Se trata, entonces, de tener al mismo tiempo una lógica anárquica y cívica, es decir, de rechazar cualquier causalidad, mandato, gobierno (arkhê) externos que impida poner y componer con otros los derechos del hombre.

A este propósito es interesante notar que Péguy, en sus tres conferencias sobre el anarquismo, rechaza, al igual que los anarquistas de su tiempo (Wilson, 1979: 19), la Declaración de los Derechos del Hombre de la Revolución francesa. La define como "burguesa", hecha por unos "burgueses revolucionarios" (Péguy, 1987: 450), pues termina "fabricando hombres separados entre sí, individuos esporádicos, sin comunicación los unos con los otros" (Péguy, 1987: 1814), concepción que está en contra de la que Vitry ha llamado la "antropología relacional” de Péguy (2015: 133). Por otro lado, esta concepción de los derechos del hombre y del ciudadano lleva, para Péguy, al triunfo del Estado, que es considerado como un individuo, como la "unificación en un individuo ficticio e imaginario" de los hombres-individuos fabricados como aislados que, de este modo, pueden componer sus relaciones solo por medio del individuo-Estado (Péguy, 1987: 1815). En este punto Péguy es claramente contrario a Hegel para el cual "el Estado es la realidad en que el individuo tiene y goza su libertad. (...) Solo en el Estado el hombre tiene existencia racional. (...) Todo el valor que el hombre tiene, toda su realidad espiritual, la tiene mediante el Estado" (1997: 101).

En contra de esta deriva estatista-hegeliana, para Péguy, los derechos, son puestos a través de un trabajo compuesto con los demás conciudadanos, 
trabajo que debe ser imputado por los beneficios civicos y universales producidos. A este propósito, como señala Vitry, para Péguy "la personalidad está en el principio de la ciudad y, al mismo tiempo, es su amenaza" (2015: 132). La civitas nace, por tanto, del civis que es su principio. Al mismo tiempo, el civis puede ser una amenaza para la civitas cuando se instala en un pensamiento politiquero ya hecho, el de funcionario-adulador del Poder dominante, puesto que, para Péguy, la fundación cívica es un trabajo que hay que recomenzar siempre de nuevo (Péguy, 1992: 1449). Si a Péguy, como escribieron los hermanos Tharaud, sus amigos desde el colegio, "le interesa a la vez la ciudad y el individuo" (1926: 156), esto significa que la autoridad de competencia anárquica del civis que no se somete a ninguna autoridad de mando, no está en contradicción con un pensamiento cívico que tiene el poder de ser constructor de la ciudad armoniosa. Esto significa que la cité harmonieuse que es la ciudad sana, laica, está co-instituida por el civis que, en cuanto es primum ius, pone actos y compone con otros sus derechos justamente porque asocia libremente su autoridad de competencia con otros hombres a través de actos que no son ni prohibidos ni comandados por el derecho estatal-penal. En este sentido se podría hablar de una especie de positivismo jurídico de Péguy, un positivismo que se debe entender según el sentido etimológico del término, como acto y derecho puesto por el sujeto (positus, ponere: "poner"), de ningún modo ligado a Comte y más bien parecido al de Kelsen (1960). De hecho, Péguy no acepta una relación cívica que se fundamente y se estructure sobre atributos ontológicos presupuestos con sus esencias que existen en sí, como meros productos de la "combinación de puros conceptos" (Péguy, 1988: 100). Lo que implica que es imposible una relación cívica entre hombres si estos viven entre sí a partir de una ontología de los derechos prefijada, de "grupo" (Péguy, 1988: 1276), la de los "políticos", de los "eclesiásticos", de los "periodistas", de los "militares", de los "pobres" y de los "burgueses", etc., pues esto llevaría inevitablemente por los caminos de la sinrazón, los de la autoridad de mando, a una lucha de clases (ontológicas) entre los hombres. De hecho, la lección jamás desmentida y contenida en la Cité harmonieuse es que los hombres trabajan con y no en contra de los demás hombres (Péguy, 1987: 
71). De este modo, los derechos del hombre son un ius semper condendum, "un trabajo continuo, continuado, proseguido en el tiempo y en la duración" (Péguy, 1988: 964), no son derechos tout fait, sino se faisant. Es una de las lecciones principales de método de Péguy que ha aprendido del método bergsoniano: hay que recomenzar siempre de nuevo, no se puede nunca estar tranquilos, nada está asegurado a priori ontológicamente (1992: 638), pues nada puede ser considerado tout fait sino que debe ser reconocido como se faisant (Péguy, 1992: 1254): "La única regla de método, lógica que hemos seguido es la de no repetirnos, de recomenzar" (Péguy, 1988: 983). En este sentido, los derechos entre los hombres se ponen y componen a través de la libertad del pensamiento que es libre de asociarse con cualquier otro sujeto para la realización de una libertad universal "libre de toda servidumbre" (Péguy, 1987: 544). En este punto se puede decir que Péguy sigue a Grave que en un artículo de 1880 había hablado del "individuo libre en la humanidad libre" (Maitron, 1951: 124).

En síntesis, esta segunda regla del pensamiento anárquico de Péguy, propone un derecho anterior al del Estado: se trata del derecho del sujeto, del civis que es libre de asociar su pensamiento a otros para que se genere una filosofia de productores, una amistad del pensamiento que debe ser juzgada-imputada por sus beneficios "económicos" universales. Hablando de la libertad del pensamiento, la de "filosofar y de hacer metafísica" asociándose libremente con otros hombres, escribe: “¿Cuándo finalmente rechazaremos recibir de las manos del Estado lo que de ningún modo es dominio-propiedad del Estado? (...) Ya no tenemos un catecismo de Estado" (1988: 564).

\section{MEMORIA Y ACONTECIMIENTO DEL PENSAMIENTO}

Esta autoridad de competencia del sujeto que funda su libertad del pensamiento, la de asociarse con cualquier hombre-socio, se arraiga históricamente en una memoria; esta es la tercera regla. A partir de 1905, año en que se hace evidente la amenaza de guerra contra Francia por parte de Alemania, lejos de cualquier conservadurismo (Grondeux, 2002; Bastaire, 
1979: 206) o de cualquier patriotismo chovinista, Péguy se arraiga en la memoria que él entiende de modo mucho más amplio que su maestro Bergson, como durée vivante (Péguy, 1988: 91). La memoria es el ámbito históricoexperiencial en que se genera y se nutre la autoridad de competencia y la libertad del pensamiento del sujeto. Estas brotan del arraigo en una patria entendida como "la tierra de los padres" (Seigle, 2014: 109). Solo de este modo, el pensamiento puede tener un "cuerpo pensante" (1988: 1069) y no ser meramente intelectual o politiquero: "No puede haber ningún pensamiento de raza que ha podido aparecer sin un cierto corpus, sin un cuerpo de pueblo" (Péguy, 1988: 1306).

¿Cómo llega Péguy a este reconocimiento de la "memoria"?

Ante todo, lejos de ver una contradicción entre revolución y tradición, para él, la primera es "esencialmente una operación de puesta en orden, o de una nueva puesta en orden (...) y toda operación de desorden es una operación de reacción que produce esclavitud" (Péguy, 1988: 65). Aquí se diferencia del anarquismo de su tiempo al que acusa de ser una mera reacción a una situación de opresión, esclavitud y explotación. Puesto que es una reacción permanece deudora del pensamiento que quiere derribar. En este sentido, nos parece equivocado definir el anarquismo de Péguy como una "sensibilidad reactiva" y definir a nuestro autor como "un hombre que reacciona frente a una realidad social opresora" (Vitry, 2015: 129-130). Al contrario, para Péguy, la verdadera revolución anárquica es una "operación de trabajo" del pensamiento (1988: 472), trabajo que consiste en "el llamado a una tradición más profunda (...) a una búsqueda de las fuentes más profundas, en sentido literal, en un renacer de las fuentes (ressource)" (Péguy, 1987: 1305).

Por otro lado, la autoridad de competencia del hombre y su libertad del pensamiento pueden generarse solo a través de la que Péguy llama repetidas veces una remontada-ascensión desde una raza cívica. "Memoria" viene, por tanto, a coincidir con el reconocimiento en el presente no de algo pasado, sino más bien de una tradición que es savia que fructifica en el presente. Esta operación de remontada desde una raza-pueblo, si por un lado parece "diluir la individualidad en un vasto anonimato sin fondo, conduce por otro lado a una 
celebración de la libertad individual" (Vitry, 2015: 119). "Memoria" es, por tanto, el brote en el presente de un pensamiento, es decir, de una autoridad de competencia y de una libertad del pensamiento que se arraiga en una tradición antigua que, para Péguy, tiene origen en la creación primera: "El hombre se vuelve a hundir en el silencio de su raza y de remontada en remontada, encuentra en ella la última prolongación del silencio eterno de la primera creación” (Péguy, 1992: 1305-1306).

Si para Péguy “conocer es conocer en comunión” (1992: 1380), la tercera regla-condición metodológica para la autoridad de competencia del hombre que no sea sumiso a ningún poder es la de arraigarse en este "inmenso pueblo silencioso, analfabeto que nutre su vida y su trabajo, su producción y su obra" (Péguy, 1988: 186-187), un arraigo que, como hemos señalado, debe ser hecho con beneficio de inventario, por una razón crítica. Por tanto, un sano pensamiento anárquico, lejos de contraponerse o despreciar al pueblo, se nutre de él, es de modo filial engendrado por el campesino francés que "es un filósofo único en el mundo, que ninguna autoridad de mando intimidará" (Péguy, 1988: 191), ya que juzga como un Papa.

Esta "memoria", este arraigo y remontada desde una raza-pueblo hace posible que el civis sea primum ius, generador de derechos y crítico de cualquier autoridad de mando. Lo dice claramente un año antes de morir: "Nosotros [Péguy habla de sí mismo] somos la tradición, la más alta autoridad, el derecho más viejo” (1992: 900).

Arraigarse en la "memoria" de un pueblo significa tener la misma mens, la del trabajo bien hecho. Por eso se ha podido afirmar que el anarquismo de Péguy mira a la "restauración del trabajo" (Wilson, 1979: 31), del trabajo bien hecho, productivo, lejos de cualquier intelectualismo utópico-anárquico. El trabajo está bien hecho cuando es producido con otros hombres. Por eso, de las tres palabras símbolo de la Revolución de 1789, la única que él conservará es fraternité (Péguy, 1987: 1033; 1237). En efecto, la égalité había sido reducida a un sistema de contabilidad que nivela a los hombres a una "igualdad artificial, abstracta, aritmética" (Péguy, 1987: 1236) por medio de una "contabilización del trabajo" (Péguy, 1987: 60). Y la liberté proclamada en 1789 había sido 
reducida a un sistema de rivalidad, emulación, competitividad, guerra de todo tipo, ambición, resentimiento, envidia, maldad (Péguy, 1987: 62-71).

Hay que señalar que, en virtud de este arraigo en la raza-pueblo de que se nutre, la autoridad de competencia del sujeto no implica una evasión de la historia como sostiene de modo equivocado Leroy (1978: 135). Siguiendo en esto a Descartes, Péguy quiere "conducir su pensamiento como una acción" (Péguy, 1992: 1267), ya que para un pensamiento en acto, para una "razón que razona, que obra" (Péguy, 1992: 857), no existe la separación entre conocimiento y acción: "Es el conocimiento, inexistente por sí mismo, que se funda en la acción, en la vida, en el ser" (Péguy, 1992: 850-854). Es en el acto puesto por el sujeto y compuesto con otros hombres que se puede comprobar la imputabilidad de los beneficios universales producidos y de los mismos derechos humanos compuestos sin necesidad de esperar o apelar a ninguna burguesa Déclaration des droit de l'homme et du citoyen de 1789.

Ahora bien, en virtud de este arraigo en la raza-pueblo de que se nutre, la autoridad de competencia del sujeto constituye para Péguy el acontecimiento del pensamiento, "el acontecimiento psicológico" (Péguy, 1988: 1111), el “acontecimiento de la vida psíquica” (Péguy, 1988: 1112). En este punto, hay que señalar que el concepto de acontecimiento (événement) en Péguy es muy original. Prolongando el pensamiento de su maestro Bergson (Molteni, 2016), Péguy combate en toda su obra el método positivista que dominaba en su tiempo (Roe, 2014) y que reducía el acontecimiento (événement) a advenimiento (avénement), a algo que proviene del exterior, a hecho bruto, neutral, genérico. Esto implicaba una "fetichización del acontecimiento entendido como exterioridad de lo que acontece" (Dosse, 2010: 39) y es lo que hacía la escuela historiográfica de la Sorbona que explicaba el acontecimiento a través de su reconducción a lo ya sabido terminando en su catalogación en fichas historiográficas. Era un pensamiento del acontecimiento meramente académico, que deducía un hecho de otro, legitimación de un discurso que servía solo para hacer carrera universitaria (Péguy, 1992: 1416).

Si Péguy habla de la "soberanía del acontecimiento" (1988: 870) es para indicar su imprevisibilidad, el hecho que no puede ser deducido de modo 
lógico, físico y científico: "Lo más imprevisto es siempre el acontecimiento" (Péguy, 1992: 124). Esta imprevisibilidad es "el secreto del acontecimiento" (Péguy, 1992: 1209), pues este no obedece a la que Péguy llama la "regla sagrada del hecho puro" (1988: 56) que es consecuencia de la visión ingenuamente positivista del tiempo entendido como geométrico-espacial. De hecho, "el acontecimiento sigue otro tiempo" (Péguy, 1992: 1033) que es el de la duración real de Bergson.

En este punto Péguy prolonga la lección de su maestro y afirma que la duración es la experiencia vivida de una raza en que el hombre se injerta. El acontecimiento está, entonces, relacionado con la tercera regla de método, la de la "memoria": el acontecimiento es comprensible solo desde dentro de la duración histórica de una raza de pensamiento. De este modo, el mismo pensamiento es acontecimiento, es un pensamiento de raza. El acontecimiento es propiamente événement no en cuanto es algo que viene desde afuera del hombre (avénement), sino en cuanto es propiamente el acontecimiento del pensamiento que se identifica con la autoridad de competencia del hombre que, arraigado libremente en una raza-pueblo, la remonta y la representa a través de su jurisdicción universal (Péguy, 1992: 254). El acontecimiento es, por tanto, operación de memoria: "La memoria está dentro del acontecimiento" (Péguy, 1992: 1178) y esta es posible solo dentro de un cuerpo-pueblo: "Queremos tocar el fondo, lo resistente, lo real. Y tenemos la impresión de no tocar el fondo hasta cuando tocamos el pueblo. (...) Solo entonces creemos que algo es verdadero, que algo es real" (Péguy, 1992: 431).

Nadie, ni el más grande genio del mundo puede esquivarse de ser engendrado en una cierta raza terrenal "donde el acontecimiento trabaja, a favor o en contra de él" (Péguy, 1992: 1314). El acontecimiento, por tanto, no consiste en una novedad extraordinaria, más bien se nutre de una tradición, de una raza que genera "una cierta experiencia del acontecimiento (événement) de las operaciones del pensamiento" (Péguy, 1992: 1280). Como ya hemos señalado, para Péguy conocer es conocer dentro de una comunión, dentro de una amistad de pensamiento. Esta es la que genera y nutre la autoridad de competencia del hombre, el acontecimiento de su pensamiento. Como ha 
escrito Mounier: "La filosofía de Péguy vivía alrededor de él en un sistema de amistades" (1993: 38). Pertenecer a una raza de pensamiento es la única posibilidad para que se genere el acontecimiento de un hombre y de un pueblo nuevo. Esto implica que la fortuna de un hombre es "estar bien posicionado" (Péguy, 1988: 1292), o sea, estar en el acontecimiento de una historia que acontece en virtud de "puntos de renovación, de profundos nuevos inicios. Este es el secreto mismo del acontecimiento. (...) De repente, donde no había nada, se está dentro de un nuevo pueblo, de un nuevo mundo, de un nuevo hombre" (Péguy, 1992: 1209).

El "acontecimiento", por tanto, está estrechamente vinculado a la "memoria" y a la autoridad de competencia que reconoce como propio, en el presente histórico, un pensamiento de raza-pueblo, o sea, el de una amistad del pensamiento. El acontecimiento del pensamiento, como queda claro en Péguy, tiene un valor cívico-político, el de la construcción de un mundo, de un hombre y de un pueblo nuevo. Es por esta razón que el anarquismo de Péguy ha defendido la "libertad del acontecimiento" (Wilson, 1979: 18).

El acontecimiento establece el mismo método de conocimiento, de pensamiento. Para Péguy no se conoce a priori: "Hay una violencia no solo inmediata que actúa a través de la violencia, sino hay una violencia metafísica (de mala metafísica) que anticipa el acontecimiento" (Péguy, 1988: 299). Es la pretensión de los métodos historiográficos de situarse "antes de la historia (l'historien avant l'histoire)" (1988: 1067). Tampoco, para Péguy, se puede conocer a posteriori (como la lechuza de Hegel: Riquier, 2017: 392): es el caso de Clío con sus “viejos dientes históricos” (Péguy, 1992: 997), es decir, de la historiografía positivista que conoce después que el acontecimiento ha sucedido (Péguy, 1954: 141) y que transforma el presente "en un problema del pasado" (Péguy, 1988: 1085). Para Péguy se trata de "estar bien situado en la historia" (1988: 1292): “Adelantarse-atrasarse, cuanta inexactitud. No hay otro modo de ser exacto que llegar a la hora" (Péguy, 1992: 1415). Propiamente, se puede solo reconocer en el presente y desde dentro del acontecimiento, pues el reconocimiento es engendrado por el mismo acontecimiento de una raza de pensamiento. En este sentido, hablando del acontecimiento-revelación 
de la amenaza de guerra alemana en 1905, afirma que ha hecho resurgir en el presente y por una especie de "casi reminiscencia platónica" lo que ya estaba en cada francés, una "certeza anterior" (Péguy, 1988; 60) que estaba en una "memoria sumergida-engullida" (mémoire engloutie) (Péguy, 1988: 61). Es la "revolución" que consiste propiamente en el acontecimiento del pensamiento, "ser mentalmente transferido en un mundo nuevo" (Péguy, 1988: 89), el mundo nuevo de la "duración real y viviente" (Péguy, 1988: 91) de un pensamiento que es memoria. Solo de este modo, el hombre "conoce", diferenciándose de quien solo "sabe" (Péguy, 1988: 1199). De hecho, el hombre de genio es justamente quien "alcanza esta realidad naciente común" (Péguy, 1988: 1165), o sea, es cualquier hombre que actúa "por cuenta de su raza, de su familia, de su sociedad, de la ciudad" (Péguy, 1988: 1170).

Una última anotación: Péguy, siguiendo su regla del trabajo compuesto, está lejos de querer pensar en lugar del pueblo como hacían los socialistas parlamentarios-populistas: "Yo no soy un intelectual que baja y condesciende con el pueblo. Yo soy pueblo. Yo trabajo con él” (Péguy, 1987: 680). Tal cual era la experiencia vivida en los Cahiers, Péguy quiere "una relación de hombre libre con otro hombre libre" (Péguy, 1987: 582), pues el acto socialistaanárquico es el que reconoce "la libertad de la razón" (Péguy, 1987: 641), del pensamiento. De hecho, en sus Cahiers quería mostrar que el "verdadero anárquico tiene un disgusto más profundo por ejercer una autoridad de mando que por sufrirla" (Péguy, 1987: 707) y, por ello, llega a afirmar que no es "un anárquico profesional" (1987: 683), es decir, un anárquico politiquero, menos aún un "anárquico estetizante" (Péguy, 1987: 311), el especialista de un anarquismo de literatura.

\section{CONSIDERACIONES FINALES Y SUGERENCIAS}

Péguy no fue, como afirma Leroy, "un hombre de izquierda que camina por la derecha" (Leroy, 1978: 135), lo que pone en duda la coherencia del pensamiento de Péguy. Este discurso, que es un lamentable y falso refrain entre algunos estudiosos de Péguy, ha sido definitivamente desmentido con 
argumentos por Finkielkraut (2012).

Péguy fue un "anarquista fiel” (Bastaire, 1979: 177-206) o, como escribe Mounier, "fue siempre fiel a su primera filosofía" (1993: 43), mejor dicho, a su método de pensar. Jamás ha abandonado las reglas de método que hemos mostrado y que hacen que no sea asimilable a ningún tipo de anarquismo presente en su tiempo (y en el nuestro) (Wilson, 1979: 23). En este sentido, Wilson escribe de modo muy pertinente: "Péguy es demasiado anarquista para ser o decirse discípulo de los teóricos anárquicos" (1979: 41). De hecho, Péguy no quiso elaborar un sistema doctrinario acerca del pensamiento anárquico, tampoco quería ser un anárquico profesional, es decir, un funcionario de la anarquía (Péguy, 1987: 398). Esto se debe al hecho de que el suyo es más bien un método de pensamiento para bien conducir la razón en materia cívica escapando a la tentación de la politiquería y del intelectualismo ahistórico. Él mismo decía que "por una reivindicación de libertad", había "administrado rigurosamente su conducta por el método libertario" (1987: 1506).

Para Péguy la cuestión del método es primordial. Es por el método que un hombre "se inscribe en la historia eterna", como ha hecho Descartes (Péguy, 1992: 1266). Si justamente se ha escrito que Péguy ha inventado un "nuevo método" de pensar (Riquier, 2014: 25), este método puede ser muy bien considerado "la heredad más importante y vital que Péguy ha dejado" (Prontera, 1988: 127). A este propósito, Vitry (2015: 127) ha hecho agudamente notar que el anarquismo de Péguy es tal en cuanto es propio del hombre-Péguy.

¿Qué sugerencias aportan a nuestro tiempo las tres reglas metodológicas del pensamiento cívico-anárquico de Péguy? Señalamos solo algunas que nos parecen importantes.

Primeramente, sugiere una reflexión sobre los métodos de conocimiento. Péguy critica la "la idea supersticiosa de que no habría ninguna certeza que la científica" (1988: 589) y habla de la instauración “de la religión de la ciencia, de la superstición de la ciencia moderna" (Péguy, 1988: 1192) que es un "sistema de conocimiento no de lo real, sino de lo verdadero (...) un verdadero que se presenta como lo único verdadero de lo real" (Péguy, 1988: 613), lo que él llama “lo verdadero científico" (Péguy 1988: 627). De 
este modo, contestando la pretensión de que los únicos métodos adecuados de conocimiento sean los positivistas con sus procedimientos estandarizados e inmutables (a la manera que los contesta el anarquismo metodológico de Feyerabend, 1976: 7), sugiere la necesidad primordial, anterior a cualquier otro saber, de elaborar un método de pensamiento cívico adecuado para la construcción de la ciudad de los hombres, puesto que "en ningún orden de conocimiento la humanidad ha esperado la ciencia" (Péguy, 1988: 1207). Su misma afirmación del acontecimiento del pensamiento que escapa a la consolidada mentalidad ontologista-estática que domina hasta nuestros días el pensamiento, aporta una sugerencia de cómo se puede pensar un método conforme al acontecimiento de un pensamiento que sea cívico, constructor de una nueva polis, de una ciudad armoniosa-sana.

En segundo lugar, Péguy cuestiona la imagen del "poder" entendido como sustantivo ("El Poder" como Idea patológica platónica), privilegio que sería solo de algunos (de una aristocracia epistemológica e intelectual), de todos (de la democracia como psicología de las masas) o de un supuesto Estadoindividuo en sentido hegeliano. De este modo sugiere la necesidad de volver a pensar la cuestión decisiva del poder entendiéndolo como verbo, como actocapacidad que pertenece, por derecho puesto y compuesto con otros, al sujeto. De no ser así, según la famosa expresión de Péguy, "la mística”, es decir, la autoridad de competencia del hombre sería devorada por la politiquería (1992: 20), o sea, "por un insaciable apetito de poder" (Fédier, 2014: 94). En este sentido, nos parece equivocado definir el anarquismo de Péguy como metapolítico (Ferrero, 2008: 51). Si bien Péguy no ha pertenecido a ningún partido político, su intención es política, la construcción de una polis armoniosa sin ninguna ambición de establecerse en "El Poder" político. De esta forma, se puede decir que, para Péguy cuanto más el sujeto reconoce el poder de su autoridad de competencia compuesta de modo libre con otros hombres, menos pretende ni necesita instalarse en "El Poder".

A este propósito, es la tercera sugerencia, el mismo concepto de soberanía debe ser reconsiderado como propiedad del pensamiento del hombre. Esta soberanía no es limitada por ninguna institución, cualquiera que 
ella fuese, como se piensa de modo genérico y superficial. El único límite a esta soberanía es más bien un pensamiento patológico, que remueve su autoridad de competencia universal-cívico-política, su libertad para generar una polis-amistad del pensamiento, su arraigo en el acontecimiento de una raza-polis en la cual se genera el pensar. La soberanía individual es por tanto un concepto político y es fundamento de cualquier otra soberanía.

De este modo y como cuarta sugerencia, las tres reglas del método anárquico-cívico de Péguy proponen relativizar el mismo concepto de "política". "El Poder" de "La Política" debe ser reconocido como muy reducido, mientras que se podría afirmar que la "política" real es extra-parlamentaria, es decir, es la política por la cual el civis construye la polis y la civitas con sus actos competentes y libres de asociarse con cualquier partner para componer relaciones productoras de beneficios universales.

La quinta sugerencia se refiere al concepto de laico. ¿Este puede ser definido solo en su forma negativa, como "quien no es sacerdote"? Para Péguy, el laico es el sujeto que, arraigado en un pueblo, es dotado de autoridad de competencia y, por su libertad de pensamiento, es libre de asociarse con cualquier otro sujeto para generar una filosofía de productores de polis.

La sexta sugerencia se refiere al rechazo por parte de Péguy de saberes que inhibirían e inhabilitarían la competencia individual del sujeto. Esto es importante sobre todo en nuestro tiempo donde se asiste a una reproposición clerical de ámbitos de saberes “sagrados” (científicos, económicos, filosóficos, teológicos, etc.) en los cuales solo algunos serían especialistas en cuanto poseedores de una episteme que excluye la autoridad de competencia del hombre común, del laico. Afirmar que el poder es propio del pensamiento laico del sujeto arraigado en un pueblo para el cual no existen ámbitos sagrados-prohibidos a su competencia, es decir, al trabajo de su pensamiento, representaría realmente un acontecimiento del pensamiento.

La séptima sugerencia invita a volver a pensar en la validez de "Los Derechos Humanos" entendidos como propiedad ontológica -ya hecha estática- del hombre. Esta concepción termina, a menudo, en la pretensión que una institución (Estado, Iglesia, partidos, sociedad, etc.) satisfaga los 
derechos que el mismo hombre no quiere tomar la iniciativa de componer libremente con otros sujetos. Para Péguy está claro que la autoridad de competencia quiere solo trabajar sin reclamar y exigir ninguna ayuda a instituciones pre-constituidas (Péguy, 1992: 791). No son las instituciones, por tanto, las que deben sostener al civis, sino que es este quien las sostiene con su poder, es decir, con su autoridad de competencia y su libertad del pensamiento, de asociación productora con otros hombres: "Un pueblo entero puede comprometer su libertad, enajenar su fecundidad, vender su raza, para comprar rentas del Estado. Pero, cuando ya no haya ni pueblo ni raza ¿dónde estará el Estado?" (Péguy, 1992: 1423). En este sentido, la misma noción de lo que es el "Derecho" debería reconocer el primum ius que es el derecho del hombre de imputar y de hacerse imputar por su jurisdicción productora, a través de un trabajo bien hecho, de beneficios universales.

Finalmente, Péguy sugiere continuar una reflexión sobre la verdadera naturaleza del pensamiento anárquico que no puede ser desclasificado fácilmente como un pensamiento irracional y anti-cívico. Feyerabend ha escrito que, si bien "el anarquismo tal vez no constituye la filosofía política más atractiva", puede ser "una medicina excelente para la epistemología y para la filosofía de la ciencia" (1986: 1). Péguy añadiría que el anarquismo, así como él lo propone de forma original, puede servir sobre todo para la elaboración de un pensamiento cívico.

\section{REFERENCIAS}

Bastaire, Jean. Charles Péguy el insurrecto. Madrid: Encuentro, 1979. Impreso.

Cahm, Eric. Péguy au début du siècle: socialiste ou anarchiste? En Jean Bastaire, Angelo Prontera \& Giuseppe Roggerone (Eds.), Péguy vivant. Lecce: Milella (1978): 107-118. Impreso.

Daudin, Claire, Boeswillwald Marie \& Rouvière Yves, Milo Max. Comprendre Péguy. Paris: Max Milo, 2013. Impreso.

Dosse, François. Renaissance de l'événement. Un défi pour l'historien: 
entre sphinx et phénix. Paris: Presses universitaires de France, 2010. Impreso.

Fédier, François. Péguy philosophe. En Camille Riquier (Ed.), Charles Péguy. Paris: Les Éditions du Cerf (2014): 85-108. Impreso.

Feyerabend, Paul Karl. Tratado contra el método. Esquema de una teoría anarquista del conocimiento. Madrid: Tecnos, 1986. Impreso.

Ferrero, Luis. Diálogo del personalismo con el anarquismo. Acontecimiento, $\mathrm{N}^{\circ}$ 88/3, Madrid (2008): 50-55. Impreso.

Finkielkraut, Alain. Sacaré a Péguy del ghetto. En Stefano Maria Paci, 30 Giorni, N 6, Roma (1992): 58-61. Impreso.

—. L'incontemporaneo. Péguy, lettore del mondo moderno. Torino: Lindau, 2012. Impreso.

— Le dreyfusisme intempestif de Charles Péguy. En: Benoît Chantre, Camille Riquier \& Frédérick Worms (Eds.). Pensée de Péguy Paris: Desclée de Brouwer (2015): 219-230. Impreso.

Grave, Jean. La société mourant et l'anarchie. París: Tresse \& Stock, 1893. Impreso.

Grondeux, Jérôme. Péguy conservateur? Mil neuf cent. Revue d'histoire intellectuelle, $\mathrm{N}^{\circ}$ 20/1, Paris (2002): 35-53. Impreso.

Hegel, Georg Wilhelm Friedrich. Lecciones sobre la filosofia de la historia universal. Madrid: Alianza Editorial, 1997. Impreso.

Kelsen, Hans, Teoría pura del derecho, Buenos Aires: Eudeba, 1960. Impreso. Leroy, Gerald. L'itinéraire politique de Péguy. En: Jean Bastaire, Angelo Prontera \& Giuseppe Roggerone (Eds.), Péguy vivant Lecce: Milella (1978): 129-136. Impreso.

Maitron, Jean. Histoire du mouvement anarchiste en France (1880-1914). Paris: Société universitaire d'éditions et de librairie, 1951. Impreso.

Molteni, Agostino. Algunas observaciones de Kierkegaard (y Péguy) sobre los periódicos. Revista de filosofia", № 5/1, Concepción (2006a): 25-30. Impreso.

- Charles Péguy y sus Cahiers de la Quinzaine. Légete, $\mathrm{N}^{\circ} 6$, Concepción (2006b): 127-133. Impreso. 
—. La ciudad armoniosa de Péguy. Revista de filosofía, $\mathrm{N}^{\circ}$ 6, Concepción (2007a): 53-65. Impreso.

- Henry Bergson. El acontecimiento del ser y del pensamiento. Revista de Filosofía, $\mathrm{N}^{\circ}$ 15/1, Concepción (2016): 69-86. Impreso.

Mounier, Emmanuel. El pensamiento de Charles Péguy, en Obras, vol. 1 (23137), Salamanca: Sígueme, 1993. Impreso.

—. Comunismo, anarquía, personalismo. Bilbao: Editorial Zero, 1973. Impreso.

Péguy, Charles. Lettres et entretiens. Paris: Editions de Paris, 1954. Impreso.

—. Euvres en prose complètes, vol. I. Paris: Gallimard, 1987. Impreso.

—. Euvres en prose complètes, vol. II. Paris: Gallimard, 1988. Impreso.

_ Euvres en prose complètes, vol. III. Paris: Gallimard, 1992. Impreso.

_ Euvres poétique et dramatiques. Paris: Gallimard, 2014. Impreso.

Prontera, Angelo. La filosofia come método. Libertà e pluralità in Péguy. Lecce: Milella, 1988. Impreso.

Riquier, Camille. Péguy philosophe, entre la passion et le devoir. Europe, 92, Paris (2014): 25-34. Impreso.

—. Philosophie de Péguy ou les mémoires d'un imbécile. Paris: Presses Universitaires de France, 2017. Impreso.

Roe, Glenn. The passion of Charles Péguy. Oxford: Oxford University Press, 2014.Impreso.

Seigle, Jean Luc. Le cheval Péguy. Un mystère. Paris: Pierre-Guillame de Roux, 2014. Impreso.

Tharaud, Jean et Jérôme. Notre cher Péguy. Paris: Plon, 1926. Impreso.

Teyssier, Aranaud. Charles Péguy, Une humanité française. Paris: Perrin, 2008. Impreso.

Vitry, Alexandre de. Péguy individualiste: remarques sur une sensibilité. En: B. Chantre, C. Riquier \& F. Worms (Eds.). Pensée de Péguy, Paris: Desclée de Brouwer (2015):119-136. Impreso.

Wilson, Nelly. Péguy et l'anarchisme. Bulletin l'Amitié Charles Péguy, ํ5, Paris (1979): 10-41. Impreso. 